\title{
Effect of Aspirin on Platelet Aggregation in Diabetes Mellitus
}

\author{
P. K. Khosla ${ }^{1}$, V. Seth ${ }^{1}$, H. K. Tiwari ${ }^{1}$ and A. K. Saraya ${ }^{2}$ \\ ${ }^{1}$ Dr. Rajendra Prashad Centre for Ophthalmic Sciences and ${ }^{2}$ Haematology Unit, Department of Pathology, \\ All-India Institute of Medical Sciences, New Delhi, India
}

\begin{abstract}
Summary. The effect of aspirin in vitro and in vivo on platelet aggregation has been studied in 13 diabetic subjects without retinopathy, 16 diabetic subjects with retinopathy and 20 ageand sex-matched control subjects. The rate, degree and duration of collagen-induced aggregation were greater in the diabetic patients $(p<0.05 ; p<0.01 ; p<0.05)$. The residual aggregation in vivo was greater in all diabetic patients with aspirin, whilst it only occurred in vitro in patients without retinopathy. A decreased latent period was seen in diabetic pa-
\end{abstract}

tients, to a greater extent in those with retinopathy. Significant differences in the rate, degree and duration of arachidonic acid-induced-aggregation were also seen in patients with retinopathy treated with aspirin ( $p<0.05 ; p<0.01 ; p<0.05$ ). Disaggregation only occurred with aspirin in vitro and was more frequently seen in normal subjects.

Key words: Platelet function, diabetic microangiopathy, aspirin effect on aggregation.
Increased platelet aggregation with ADP has been shown in diabetic patients with retinopathy $[1,5,7,9$, 11]. Aspirin, a cyclo-oxygenase inhibitor [12], inhibits collagen-induced aggregation [19] as well as production of arachidonic acid-induced labile aggregation stimulation substance $[17,18]$. It also inhibits secondary aggregation in diabetic patients [13]. This study was carried out to evaluate the inhibitory effect of aspirin in vitro and in vivo on platelet aggregation induced by collagen and arachidonic acid in diabetic patients with and without retinopathy.

\section{Materials and Methods}

Twenty-nine diabetic patients have been studied. Each patient had a detailed clinical examination and investigations to assess the extent of retinopathy and the severity of diabetes. Serum cholesterol, and fasting and post-prandial blood glucose levels were determined by standard techniques. Routine urine examination was also carried out. Fluoroscein angiography was used to identify patients with proliferative and background retinopathy. The disc was not involved in all cases. None of the patients had hypertension or vascular disease.

Two groups of patients were studied. Group I consisted of $13 \mathrm{di}-$ abetic patients without retinopathy. The average age of the patients was $53.6 \pm 9.4$ years, and the mean duration of diabetes was 4.7 years. Group 2 consisted of 16 diabetic patients with retinopathy. The average was $53.2 \pm 12.4$ years and mean duration of diabetes was 7.3 years. All were Type 2 (non-insulin-dependent) diabetic patients. Control subjects were healthy laboratory workers, doctors, and healthy subjects without diabetes or hypertension. None of these had tak- en any drugs known to affect platelet aggregation for 10 days before the study. The platelet aggregation was studied by the method of Born [2] using an aggregometer (Chronolog Corporation, Havertown, Pennsylvania, USA). The change in optical density and the increment rate of aggregation were computed by the differentiometer connected to the aggregometer.

Platelet aggregation was studied with $1 \mu \mathrm{g}$ collagen (collagen reagent Hormon, Munich, FGR) and with $300 \mu \mathrm{g}$ arachidonic acid (Sigma) in dimethyl sulphoxide (Sigma) per $\mathrm{ml}$ of platelet-rich plasma. The requisite amount (collagen $0.4 \mu \mathrm{g}$ and arachidonic acid $120 \mu \mathrm{g}$ ) in $0.02 \mathrm{ml}$ volume was added to $0.4 \mathrm{ml}$ platelet-rich plasma (platelet count $300,000 \mu l)$ contained in a cuvette. Study of platelet aggregation was carried out within $2 \mathrm{~h}$ of blood collection.

The inhibitory effect of aspirin in vivo was studied by the administration of a total dose of $900 \mathrm{mg}$ ( $450 \mathrm{mg}$ each day) over 2 days to patients and normal subjects. Platelet aggregation was studied $48 \mathrm{~h}$ after the first dose of aspirin. The effect of aspirin in vitro was studied with $2 \mathrm{mg}$ in $20 \mu \mathrm{l}$ of distilled water added to $0.4 \mathrm{ml}$ platelet-rich plasma and incubated for $10 \mathrm{~min}$ at room temperature. Both collagen $(1 \mu \mathrm{g})$ and arachidonic acid $(300 \mu \mathrm{g})$ induced aggregation were studied with aspirin in vivo and in vitro.

Graphic recordings were analysed statistically with respect to the latent period, rate of aggregation, degree of aggregation, duration of aggregation and disaggregation. These parameters have been described previously [7].

\section{Results}

The discriminating parameters were rate and degree of aggregation and latent period with collagen alone and on addition of aspirin in vivo and in vitro. Rate and degree were also discriminatory between normal subjects 
Table 1. Collagen $(1 \mathrm{\mu g})$-induced-platelet aggregation in normal subjects and in diabetic patients with and without retinopathy

\begin{tabular}{|c|c|c|c|c|}
\hline & \multicolumn{4}{|l|}{ Aggregation } \\
\hline $\begin{array}{l}\text { Patients without retinopathy } \\
\text { (group } 1, n=13 \text { ) }\end{array}$ & $\begin{array}{c}57.05 \pm 12.59 \\
(34.81-71.94)\end{array}$ & $\begin{array}{c}57.75 \pm 7.41 \\
(37.86-65.00)\end{array}$ & $\begin{array}{l}197.70 \pm 31.39^{\mathrm{cd}} \\
(159.23-230.76)\end{array}$ & $\begin{array}{c}37.47 \pm 11.39 \\
(24.38-60.00)\end{array}$ \\
\hline$p$ values & $a<0.05$ & $b<0.01$ & $\begin{array}{l}\mathrm{c}<0.05 \\
\mathrm{~d}<0.05\end{array}$ & ${ }^{e}<0.05$ \\
\hline
\end{tabular}

Results expressed as mean $\pm \mathrm{SD}$; Range in parentheses

and patients with arachidonic-acid induced aggregation without aspirin as well as with it, both in vitro and in vivo. Duration of aggregation was discriminatory with collagen alone and with aspirin in vitro but not with arachidonic acid.

In diabetes (group 1), the duration of aggregation with collagen was significantly increased compared with normal subjects and group 2 patients (Table 1). With arachidonic acid rate of aggregation alone was increased (Table 2). Disaggregation was seen in two of the four patients and four of the ten normal subjects.

In patients with diabetic retinopathy (group 2), a significant increase was noted in the rate $(p<0.05)$ and degree $(p<0.01)$ of collagen-induced aggregation compared with normal subjects. The latent period was shortened (Table 1). Duration of aggregation was the same as in normal subjects. With arachidonic acid, rate $(p<0.01)$ and degree $(p<0.01)$ of aggregation were significantly higher than in normal subjects (Table 2). The degree of aggregation was also higher than in group $1(p<0.01)$. Disaggregation was not seen with arachidonic acid.

\section{Effect of Aspirin in Vitro and in Vivo on Collagen and Arachidonic Acid Induced-Platelet Aggregation}

In normal subjects, the rate, degree and duration of aggregation were reduced with collagen and aspirin added in vitro. They were absent in five of them (36\%) (Table 3). Aspirin in vivo had a less marked effect on all three parameters of platelet aggregation (Table 3 ). It was absent in one of the normal subjects. A lesser degree of platelet aggregation was seen with arachidonic acid and aspirin, but it was more marked with aspirin in vivo (Table 4). The rate and duration of aggregation were also less. Disaggregation, however, occurred in nine $(90 \%)$ with aspirin in vitro but in none with aspirin in vivo.

In diabetic patients (group 1) the rate, degree and duration of collagen-induced platelet aggregation with aspirin in vitro were reduced as in normal subjects (Table 3 ), but the rate and degree of aggregation with aspirin in vivo were significantly higher than in normal subjects ( $p<0.01$; Table 3 ). The latent period was also reduced. No significant difference was found in the duration of aggregation. The degree of aggregation was reduced both with aspirin and arachidonic acid in vivo and in vitro (Table 4). No significant change was seen either in the rate, degree or duration of aggregation compared with normal subjects. Disaggregation, however, was seen in three patients (75\%) with aspirin in vitro, but in none with aspirin in vivo.

In patients with diabetic retinopathy (group 2), the degree of collagen-induced-aggregation with aspirin in vitro and in vivo was higher than in normal subjects (Table 3). A significantly higher rate and duration of aggregation were seen with aspirin in vitro $(p<0.05$; Table 3). The latent period was less when compared with normal subjects both with aspirin in vitro and in vivo (Table 3). Absence of aggregation was seen in one of the ten patients with aspirin in vitro. The rate, degree and duration of aggregation with arachidonic acid and aspirin in vivo were significantly higher than in normal subjects ( $p<0.05 ; p<0.01 ; p<0.05$; Table 4$)$. With aspirin in vitro a higher degree of aggregation was of borderline significance ( $p \approx 0.05$; Table 4$)$. Disaggregation was seen in five of eight patients $(63 \%)$ with aspirin in vitro but in none with aspirin in vivo.

\section{Discussion}

Platelet aggregation in diabetic patients without retinopathy showed a greater duration with collagen and a higher rate with arachidonic acid than in normal subjects. Disaggregation was similar in both groups. In patients with diabetic retinopathy, the rate and degree were both higher with collagen and arachidonic acid, but disaggregation was absent with the latter.

Collagen-induced aggregation is brought about by different mechanisms, namely secretion of dense granules, mainly ADP [6], synthesis of thromboxane A2 [3] and platelet activating factor acether pathway [4]. Arachidonic acid-induced aggregation, brought about by 
Table 2. Arachidonic acid-induced platelet aggregation in normal subjects and in diabetic patients with and without retinopathy

\begin{tabular}{|c|c|c|c|}
\hline & \multicolumn{3}{|l|}{ Aggregation } \\
\hline $\begin{array}{l}\text { Patients without retinopathy } \\
\text { (group } 1, n=4 \text { ) }\end{array}$ & $\begin{array}{r}91.53 \pm 28.64^{\mathrm{a}} \\
(60.06-129.20)\end{array}$ & $\begin{array}{r}38.29 \pm 17.16^{\mathrm{d}} \\
(25.80-62.40)\end{array}$ & $\begin{array}{l}125.33 \pm 104.25 \\
(34.61-256.15)\end{array}$ \\
\hline$p$ values & $\begin{array}{l}a<0.05 \\
b<0.01\end{array}$ & $\begin{array}{l}\mathrm{c}<0.01 \\
\mathrm{~d}<0.01\end{array}$ & $\mathrm{NS}$ \\
\hline
\end{tabular}

Results expressed as mean $\pm \mathrm{SD}$; range in parentheses; NS = not significant

Table 3. Platelet aggregation in normal subjects and diabetic patients with and without retinopathy with collagen (1 $\mu \mathrm{g})$ and aspirin $(2 \mathrm{mg})$ in vitro and $(900 \mathrm{mg})$ in vivo

\begin{tabular}{|c|c|c|c|c|c|c|c|}
\hline \multicolumn{8}{|c|}{ Aggregation } \\
\hline \multicolumn{2}{|c|}{$\begin{array}{l}\text { Rate (No. of } \\
\text { divisions/min) }\end{array}$} & \multicolumn{2}{|l|}{$\begin{array}{l}\text { Degree } \\
(\%)\end{array}$} & \multicolumn{2}{|c|}{$\begin{array}{l}\text { Duration } \\
\text { (s) }\end{array}$} & \multicolumn{2}{|c|}{$\begin{array}{l}\text { Latent period } \\
\text { (s) }\end{array}$} \\
\hline $\begin{array}{l}\text { Aspirin } \\
\text { in vitro }\end{array}$ & $\begin{array}{l}\text { Aspirin } \\
\text { in vivo }\end{array}$ & $\begin{array}{l}\text { Aspirin } \\
\text { in vitro }\end{array}$ & $\begin{array}{l}\text { Aspirin } \\
\text { in vivo }\end{array}$ & $\begin{array}{l}\text { Aspirin } \\
\text { in vitro }\end{array}$ & $\begin{array}{l}\text { Aspirin } \\
\text { in vivo }\end{array}$ & $\begin{array}{l}\text { Aspirin } \\
\text { in vitro }\end{array}$ & $\begin{array}{l}\text { Aspirin } \\
\text { in vivo }\end{array}$ \\
\hline
\end{tabular}

Normal subjects with aspirin in vitro

$(n=14)^{1}$ and with aspirin in vivo $(n=10)^{2}$

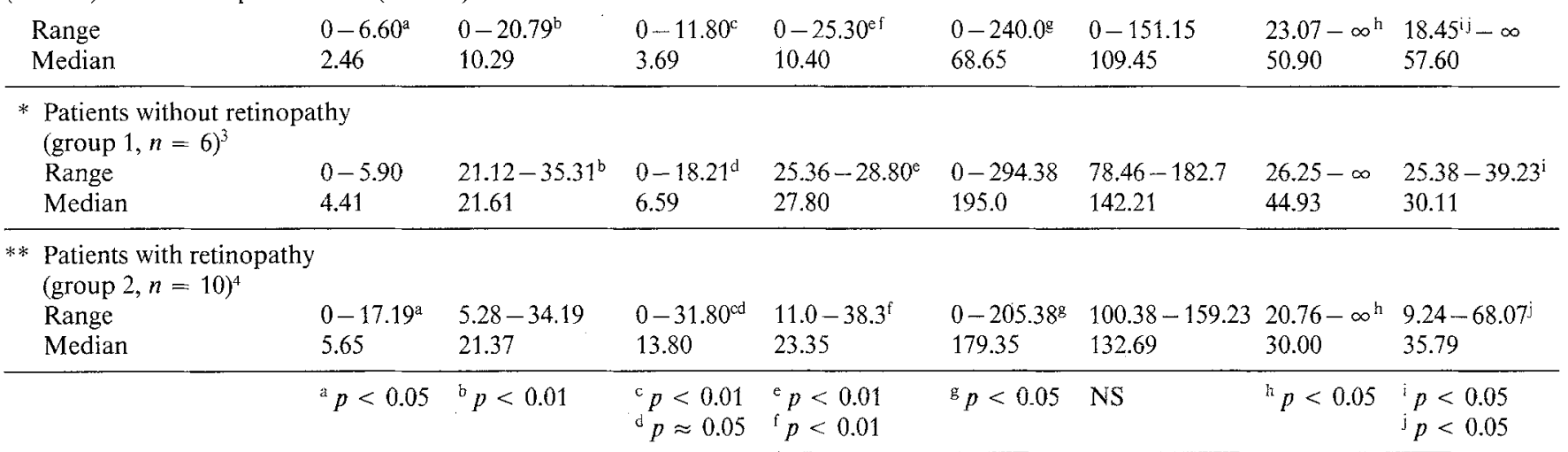

${ }^{1}$ No aggregation in five normal subjects; ${ }^{2}$ No aggregation in one normal subject; 3,4 No aggregation in one case each with aspirin in vitro * Studies with aspirin in vitro six cases and in vivo four cases; ** Studies with aspirin in vitro ten cases and in vivo eight cases; NS = not significant

Table 4. Rate, degree and duration of arachidonic acid-induced platelet aggregation with aspirin (2 $\mathrm{mg}$ ) in vitro and (900 mg) in vivo aspirin in normal subjects and diabetic patients with and without retinopathy



Results expressed as mean $\pm \mathrm{SD}$; Range in parentheses; $\mathrm{NS}=$ not significant 
the production of labile aggregation stimulating substances [17, 18], is associated with ADP scretion [15, 16] and acts synergistically [8]. It is therefore possible that increased prostaglandin synthesis and increased ADP secretion could be mechanisms for hyperaggregation of platelets. Prostaglandin metabolism, tested by aspirin (as an inhibitor of cyclo-oxygenase) in vitro and in vivo, was accelerated in patients with diabetes. The residual aggregation with collagen was greater in diabetic patients. Reduction in the degree and duration of arachidonic acid-induced aggregation by aspirin was also seen, but residual aggregation was higher in diabetic patients, more consistently in those with retinopathy, and with aspirin in vivo. Disaggregation only occurred with aspirin in vitro and was seen more frequently in normal subjects. Lesser inhibition of cyclo-oxygenase in these patients by aspirin could be due to increased cyclo-oxygenase activity in diabetic patients which may result in hyperaggregation of platelets with collagen and arachidonic acid. A combination of adequate prostaglandin endoperoxide and thromboxane $\mathrm{A} 2$ formation accompanied by release reaction $[10,14]$ could contribute to the absence of disaggregation with aspirin in vivo in patients with retinopathy.

The decreased latent period found in diabetic patients, particularly in those with retinopathy, suggests that membrane changes preceding the release reaction are independent of the presence of aspirin. A shorter latent period with ADP was observed in our earlier study [7]. It appears likely, that accelerated intrinsic ADP release does not influence directly the latent period.

In conclusion, increased platelet aggregation in diabetes could result from one or more of these proposed mechanisms, namely; reduction in the induction phase of aggregation, increase in cyclo-oxygenase activity and accelerated intrinsic $A D P$ release.

\section{References}

1. Bensoussan D, Levy-Toledano S, Passa P, Caen J, Canivet J (1975) Platelet hyperaggregation and increased plasma level of vonWillebrand factor in diabetics and retinopathy. Diabetologia 11: 307-312

2. Born GVR (1962) Aggregation of blood platelets by adenosine diphosphate and its reversal. Nature 194: 927-929

3. Charo IF, Feinman RD, Detwiler TC, Smith JB, Ingerman CM, Silver MJ (1977) Prostaglandin endoperoxides and thromboxane A2 can induce platelet aggregation in the absence of secretion. Nature 269: 66-69

4. Chignard M, Le Couedic JP, Varaftig BB, Benveniste J (1980) Platelet activating factor (PAF-acether) secretion from platelets: effect of aggregating agents. Br J Haematol 46:455-464
5. Heath H, Brigden WD, Canever JV, Pollock J, Hunter PR, Kelsey $\mathrm{J}$, Bloom A (1971) Platelet adhesiveness and aggregation in relation to diabetic retinopathy. Diabetologia 7: 308-315

6. Holmsen H (1965) Collagen induced release of adenosine diphosphate from blood platelets incubated with radioactive phosphate in vitro. Scand J Clin Lab Invest 17: 239-246

7. Khosla PK, Mahabaleshwara M, Tiwari HK, Saraya AK (1979) Platelet aggregation and retinal microangiopathy in diabetes and hypertension. Acta Haematol 61: 161-167

8. Kinlough-Rathbone RL, Packham MA, Mustard JF (1977) Synergism between platelet aggregating agents. The role of arachidonate pathway. Thrombosis Res 11:567-580

9. Kwann HC, Colwell JA, Cruz S, Suwanwela N, Dobbie JG (1972) Increased platelet aggregation in diabetes mellitus. $\mathrm{J}$ Lab Clin Med 80: 236-246

10. Marcus AJ (1978) The role of lipids in platelet function with particular reference to the arachidonic acid pathway. J Lip Res 19: 793-826

11. Passa P, Bensoussan D, Levy-Toledano S, Caen J, Canivet J (1974) Study of platelet aggregation during diabetic retinopathy. Influence of hypophysectomy. Atherosclerosis 19:277-285

12. Rome LH, Lands WEM, Roth GJ, Majerus PW (1976) Aspirin as a quantitative acetylating agent for the fatty acid oxygenase that forms prostaglandins. Prostaglandins 11: 23-30

13. Sagel J, Colwell JA, Crook L, Laimins M (1975) Increased platelet aggregation in early diabetes mellitus. Ann Int Med 82:733-738

14. Samuelsson B (1977) The role of prostaglandin endoperoxides and thromboxanes as bioregulators. In: Kharasch N, Fried J (eds) Biochemical aspects of prostaglandins and thromboxanes. Proceedings Intra-science Symposium on New Biochemistry of prostaglandins and thromboxanes, Santa Monica, CA (1976). Academic Press, New York, pp 133-154

15. Silver MJ, Smith JB, Ingerman C, Kocsis JJ (1973) Arachidonic acid induced human platelet aggregation and prostaglandin formation. Prostaglandins 4: 863-875

16. Smith JB, Ingerman C, Kocsis JJ, Silver MJ (1974) Formation of an intermediate in prostaglandin biosynthesis and its association with the platelet release reaction. J Clin Invest 53: 1468-1472

17. Willis AL, Kuhn DC (1974) A new potential mediator of arterial thrombosis whose biosynthesis is inhibited by aspirin. Prostaglandins 4: $127-130$

18. Willis AK, Vane FM, Kuhn DC, Scott CG, Petrin M (1974) An endoperoxide aggregator (LASS) Formed platelets in response to thrombotic stimuli: purification, identification and unique biological significance. Prostaglandins 8: 453-507

19. Zucker MB, Peterson J (1968) Inhibition of adenosine diphosphate induced secondary aggregation and other platelet functions by acetyl-salicylic acid ingestion. Proc Soc Exp Biol Med 127: 543-551

Received: 17 August 1981

and in revised form: 23 March 1982

Professor A. K. Saraya

Haematology Unit

Department of Pathology

All India Institute of Medical Sciences

Ansari Nagar

New Delhi 110029, India 